\title{
Hydrocarbon Cracking Over Red Mud and Modified Red Mud Samples
}

\author{
A. I. Alharthi ${ }^{1}$ J. S. J. Hargreaves ${ }^{1}$ I. D. Pulford ${ }^{1} \cdot$ N. Gupta ${ }^{2}$ M. Balakrishnan ${ }^{2}$ \\ V. S. Batra ${ }^{2}$ R. K. Singh ${ }^{2}$
}

Published online: 19 August 2016

(C) The Minerals, Metals \& Materials Society (TMS) 2016

\begin{abstract}
The aluminum industry generates large quantities of red mud during the beneficiation of bauxite ore. The red mud is disposed of as a waste in dry or wet form. Given the issues with its disposal due to the large volume and high alkalinity, many research groups and industries have examined the use of red mud for different applications. The use of red mud as a pre-catalyst for the cracking of hydrocarbon leads to hydrogen formation and carbon deposition. Our earlier studies have shown its activity for reaction with methane and the formation of magnetic materials containing iron, iron carbide, and nanocarbon species. In this study, two aspects were studied: one was methane cracking over red mud, modified red mud, and waste from a nailwork factory site and the other was the application of different hydrocarbons, including nitrogencontaining precursors over red mud. Preliminary characterization of the resulting carbon deposits was performed. The activity for methane cracking increased when the red mud was activated and reduced before the reaction. Nitrogen-containing reactants led to the formation of
\end{abstract}

The contributing editor for this article was Yiannis Pontikes.

Electronic supplementary material The online version of this article (doi:10.1007/s40831-016-0082-4) contains supplementary material, which is available to authorized users.

J. S. J. Hargreaves

Justin.Hargreaves@glasgow.ac.uk

$凶$ V.S. Batra

vidyasb@teri.res.in

1 WestCHEM, School of Chemistry, University of Glasgow, Glasgow G12 8QQ, UK

2 The Energy and Resources Institute, India Habitat Centre, Lodi Road, New Delhi 110003, India nitrogen-doped carbon nanotubes. The nitrogen amount and morphology varied with the precursor used and the reaction temperature. This is an attractive application with potential for further modification of the carbon deposits for other catalytic and electrochemical applications.

Keywords Hydrocarbon cracking · Carbon nanotubes . Nitrogen doping

\section{Introduction}

Red mud is generated during beneficiation of bauxite ore by the aluminum industry and its valorization has attracted a lot of attention given the large volumes generated and the high alkalinity. Its application in different fields and its catalytic applications have been reviewed [1-3]. As an adsorbent, red mud has been studied for the removal of nitrate, phosphate, heavy metals, and organic substances from aqueous systems. The presence of iron compounds in red mud makes it a potential catalyst, and its application in hydrogenation, liquefaction, hydrodechlorination, hydrocarbon cracking, VOC oxidation, and pyrolysis has been studied. Different chemical and thermal treatments have been applied to improve the performance. In some processes, red mud has been applied directly where it generally functions as a pre-catalyst being transformed under reaction conditions to the active phase [4]. Other approaches have involved its pretreatment to enhance the performance or its application as a support for catalytically active phases [3]. When used directly, the spatial and temporal compositional variation of red mud sources must be taken into consideration since these may influence the catalytic performance. However, since it is such a cheap and abundant resource, it may be possible to accommodate such variations in behavior. By its very nature 
and given the large volumes of red mud produced on an annual basis, on its own, catalytic application of red mud does not offer a solution to its disposal and storage problems. However, it possibly does provide a component to the overall solution.

In our previous work, we have used unmodified red mud from different sources in India for cracking of methane. The hydrogen generation, the carbon deposition on red mud after exposure, and its application in heavy metal removal were discussed [4-6]. In this way, it was shown that two waste products-red mud and methane (a byproduct of refinery operations and of landfill dumping) could be combined to yield hydrogen and also a magnetic carboncontaining composite which has the potential for further application. In terms of the latter material, the form of carbon produced was generally graphitic, which limits further application. There is therefore potential importance in the production of more highly functionalized carbons, such as those containing structural nitrogen species, and also in the determination of the performance for the production of composite carbon products from other hydrocarbons. Furthermore, it is of interest to determine whether modifications of red mud can be made to both potentially enhance catalytic performance and also possibly mitigate variations from different red mud sources. Additional interest lies in the possible application of other iron-containing wastes for hydrocarbon decomposition. In this manuscript, some of these aspects are detailed including the application of toluene as an alternative carbon source, the use of acetonitrile as a reagent-either alone or in conjunction with other carbon-containing feeds-to introduce nitrogen functionality into the resultant carbon products, studies of the effect of modification on the red mud upon its efficacy and comparison with the historical legacy iron-containing waste from a former nailworks site. Preliminary characterization of carbon has been undertaken and its further characterization and application will form part of another study.

\section{Experimental Procedure}

The starting red mud was RM7 which has been characterized previously [4]. Toluene exposure was undertaken in a fixed bed reactor. Nitrogen at a flow rate of $100 \mathrm{ml} \mathrm{min}{ }^{-1}$ was saturated with toluene at ambient temperature and passed over $1 \mathrm{ml}$ of red mud in a fixed bed reactor maintained at the temperatures of 700 and $800{ }^{\circ} \mathrm{C}$ for different durations. The toluene conversion experiment was undertaken in a heating cycle and the reactor was maintained for about an hour at each temperature. The toluene conversion at different times was estimated by the difference in the toluene inlet and outlet peaks in a gas chromatograph (Nucon, India). The theoretical toluene concentration assuming attainment of equilibrium is $4.8 \%$. For obtaining nitrogen-doped carbon deposits, different nitrogen-containing precursors were used, i.e., acetonitrile in argon, acetonitrile in methane, and a mixture of acetonitrile and benzene in argon. The saturated gas was passed over $0.4 \mathrm{~g}$ of catalyst at a volumetric flow rate of $24 \mathrm{ml} / \mathrm{min}$ at 700,800 , and $900^{\circ} \mathrm{C}$ for different time durations till the back pressure buildup took place. The estimated acetonitrile concentration is around $200 \mathrm{ppm}$. In this set of experiments, the objective was to understand the effect of different hydrocarbons on carbon deposits.

Three types of modified red mud were used for methane cracking. Activated red mud (ARM) was obtained by boiling $\mathrm{RM} 7$ in dilute $\mathrm{HCl}$, precipitating the iron-rich material from the solution by increasing the $\mathrm{pH}$ value to 8 and calcining the precipitate in air at $500{ }^{\circ} \mathrm{C}$ for $2 \mathrm{~h}$. Reduced red mud (RRM) was obtained by passing a $1: 3$ mixture of $\mathrm{H}_{2}$ and $\mathrm{N}_{2}$ at 0.2 standard liters per minute (slpm) through the reactor at $800^{\circ} \mathrm{C}$ for $5 \mathrm{~h}$. To obtain reduced activated red mud (RARM), the activated red mud was subjected to reduction in hydrogen. The modified red mud was subjected to methane flow of $0.2 \mathrm{slpm}$ at 700 , 800 , and $900^{\circ} \mathrm{C}$. A sample from a former nailwork factory site (at Lennoxtown in Scotland) was also used. The sample was tested and compared with unmodified red mud for methane decomposition using the procedure detailed elsewhere [4]. The $\mathrm{H}_{2}$ quantification was undertaken using online GC (Hewlett Packard 5890A) provided with a TCD and a Molecular Sieve 13X packed column. The sample after sieving and washing was oven dried to obtain a fine brown powder.

The samples after reaction were typically characterized by scanning electron microscopy (XL30 ESEM Phillips microscope), thermal analysis in an atmosphere of $20 \%$ oxygen and balance nitrogen (TA Instruments, Q500), CHN analysis (CE-440 Elemental Analyzer), and powder $\mathrm{X}$-ray diffraction (Siemens D5000 diffractometer with $\mathrm{Cu}$ $\mathrm{K} \alpha$ radiation). ICP optical emission spectroscopy (ICP$\mathrm{OES})$ was used to obtain information regarding the elemental composition of the samples. The ICP-OES instrument used in this work was an ICPS-7000 Shimadzu instrument. Approximately $0.3 \mathrm{~g}$ of the sample as well as certified reference material, Soil IAEA 7, was placed in a Teflon ${ }^{\mathrm{TM}}$ pressure vessel, and $6 \mathrm{ml}$ nitric acid $(65 \%$ extra pure, Riedel-Deltaën) and $4 \mathrm{ml}$ hydrofluoric acid (40\%, Qualikems) were added. The vessels were capped, sealed, and heated following the digestion method cycles reported elsewhere with some modification [7], and the vessels were then cooled down for $2 \mathrm{~h}$. Aqua regia solution was used to complete the digestion, where $12 \mathrm{ml}$ of aqua regia was added to the samples. Each vessel was sealed and heated, which followed the above procedure. After digestion, the 
samples were transferred to a volumetric flask and diluted with deionized water to $100 \mathrm{ml}$. Surface areas were determined using a Micromeritics Gemini instrument by application of the BET method to nitrogen physisorption isotherms determined at $-196{ }^{\circ} \mathrm{C}$ following sample outgassing at $110{ }^{\circ} \mathrm{C}$ overnight.

\section{Results and Discussion}

The results from RM7 exposed to toluene are shown in Figs. 1, 2, 3, and 4. XRD analysis undertaken on samples exposed to toluene typically corresponded to reduced oxide products of hematite (magnetite, wustite), iron, and iron carbide along with graphitic carbon depending on the temperature of exposure. At $700{ }^{\circ} \mathrm{C}$, the main phases were magnetite and wustite, while at $800{ }^{\circ} \mathrm{C}$, the main peaks were graphite, iron, and iron carbide (Fig. 1). The sample also showed cracking of toluene which is illustrated in the conversion curve in Fig. 2. The SEM images (Fig. 3) of the $800{ }^{\circ} \mathrm{C}$ sample shows the presence of some filaments corresponding to the presence of graphite in the form of CNTs in this sample. This was consistent with thermal analysis which revealed weight loss in the temperature

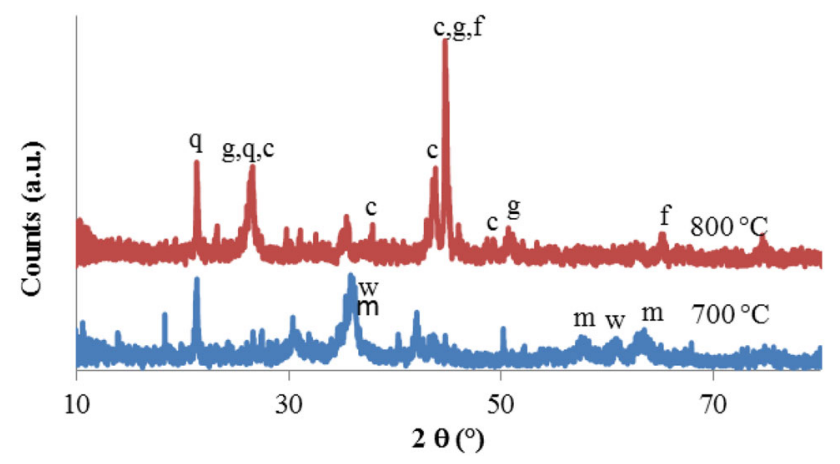

Fig. 1 XRD pattern of red mud exposed to toluene at different temperatures (m-magnetite $\mathrm{Fe}_{3} \mathrm{O}_{4}$, w-wustite $\mathrm{FeO}$, g-cliftonite $\mathrm{C}$, q-quartz $\mathrm{SiO}_{2}$, c-iron carbide $\mathrm{Fe}_{3} \mathrm{C}$, f-iron $\mathrm{Fe}$ ) (from Ref. [8])

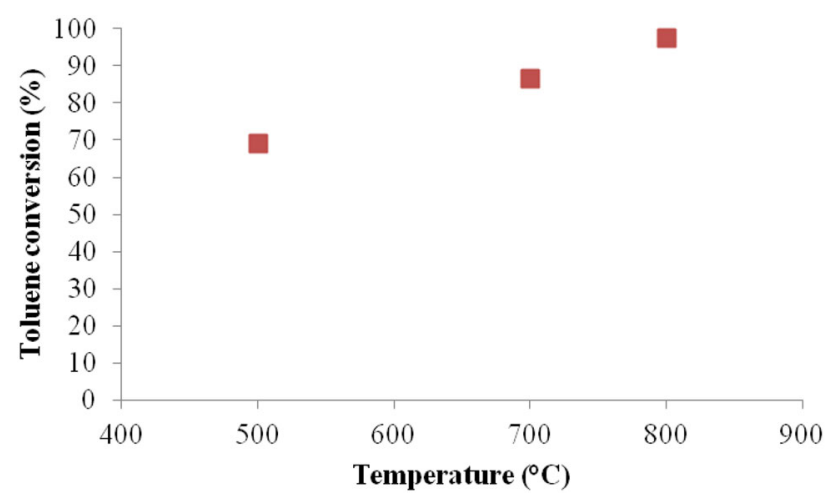

Fig. 2 Toluene conversion as a function of temperature by red mud

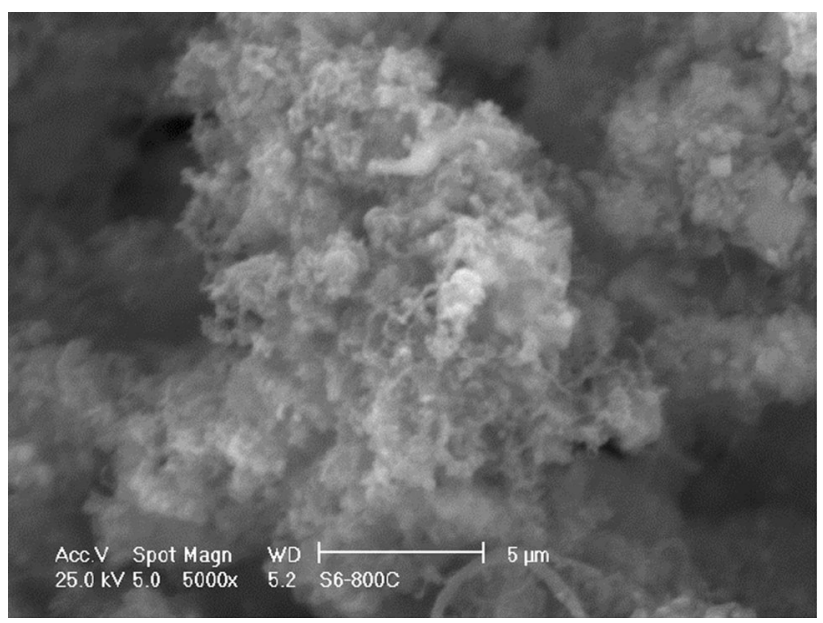

Fig. 3 SEM image of red mud exposed to toluene at $800{ }^{\circ} \mathrm{C}$

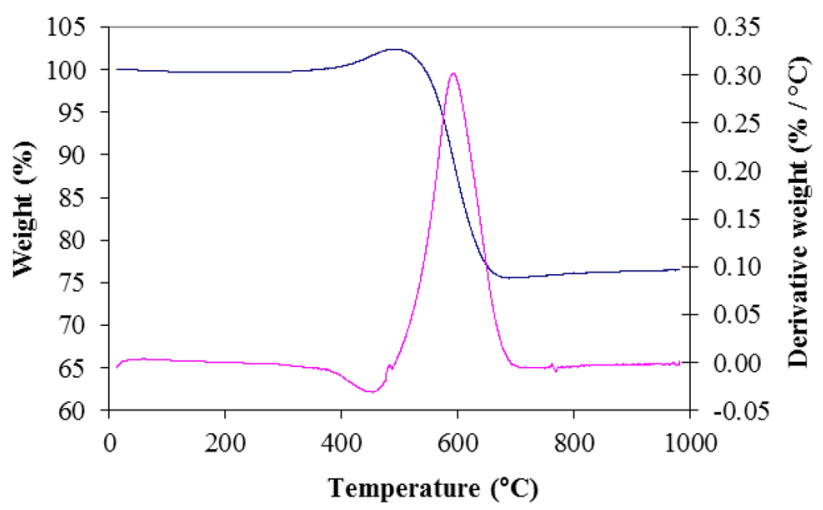

Fig. 4 TGA profile of red mud exposed to toluene at $800{ }^{\circ} \mathrm{C}$ (from Ref. [8])

range $450-650{ }^{\circ} \mathrm{C}$ due to oxidation of carbon (Fig. 4). The slight increase in weight at around $350{ }^{\circ} \mathrm{C}$ could be due to oxidation of low-valent iron oxide (wustite).

The use of a nitrogen-containing precursor with RM7 led to the incorporation of $\mathrm{N}$ in the carbon deposit. In the case of acetonitrile, the maximum $\mathrm{C}(67.9 \%)$ and $\mathrm{N}$ $\left(1.8 \%\right.$ ) deposition occurs at $800{ }^{\circ} \mathrm{C}$ (after $12 \mathrm{~h}$ on stream). When methane is used as the carrier for the acetonitrile, there is no nitrogen observed at higher temperatures ( 800 and $900{ }^{\circ} \mathrm{C}$ ) and the amount of carbon deposited is less compared to that with only acetonitrile (in the range of 12 to ca. $40 \%$ after $3 \mathrm{~h}$ on stream). This observation has been supported by the literature $[9,10]$ where it has been reported that the presence of hydrogen can lead to the formation of $\mathrm{HCN}$ which reduces the doping of nitrogen. With the addition of benzene to acetonitrile, there is a decrease in the overall amount of carbon deposited (carbon content in the range of 17 to ca. $48 . \%$ after $6 \mathrm{~h}$ on stream), but nitrogen content in the CNTs is observed at higher temperature $\left(0.57 \%\right.$ at $\left.900{ }^{\circ} \mathrm{C}\right)$. TEM analysis of samples 


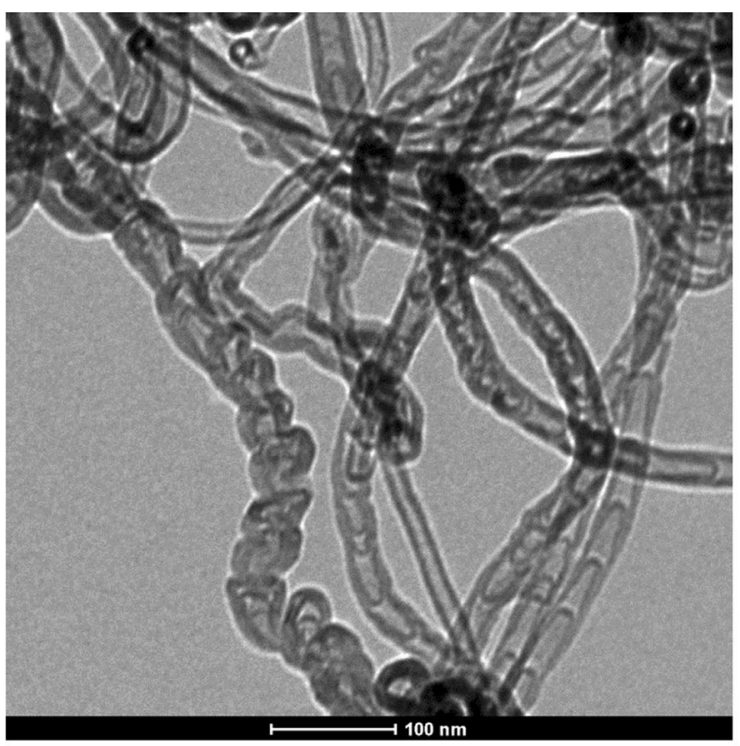

(a)

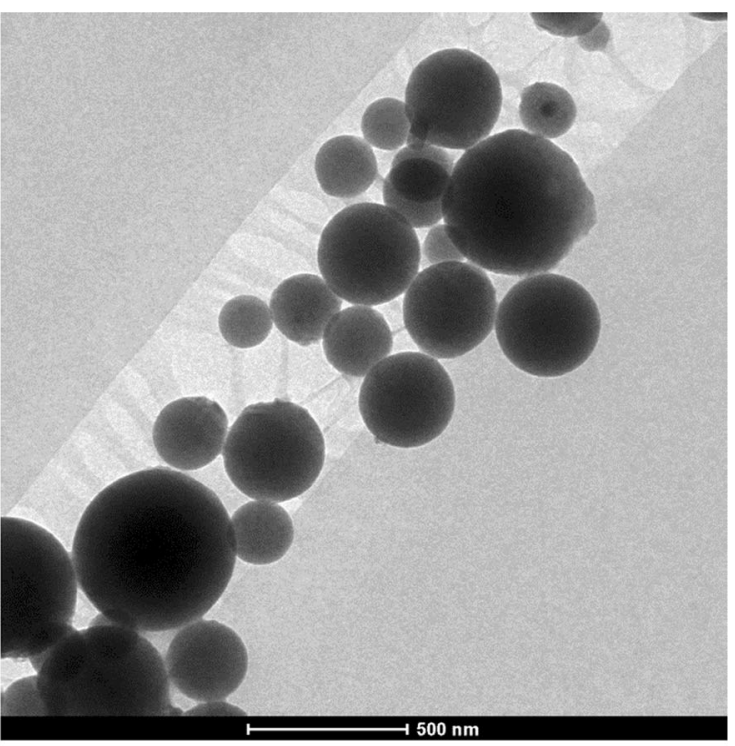

(b)

Fig. 5 TEM images of nanocarbons forming from reaction with acetonitrile at a temperature of $\mathbf{a} 800{ }^{\circ} \mathrm{C}$ and $\mathbf{b} 900{ }^{\circ} \mathrm{C}$ and using a flow rate of $24 \mathrm{ml} / \mathrm{min}$

prepared with acetonitrile showed a bamboo-like structure at $800{ }^{\circ} \mathrm{C}$, while the samples prepared at $900{ }^{\circ} \mathrm{C}$ also comprised carbon spheres (Fig. 5). There appeared to be no amorphous carbon in these samples. XPS spectroscopy undertaken in the $\mathrm{N} 1 \mathrm{~s}$ region and presented as Supplementary Information for the sample prepared at $800{ }^{\circ} \mathrm{C}$ suggests that there are possibly different nitrogen environments in the sample, demonstrating that there is a degree of heterogeneity in this respect which could impact upon its further utilization.

The cracking of methane measured in terms of hydrogen formation rate showed different behaviors based on the pretreatment used (Fig. 6). Reduced activated red mud showed the highest activity compared to the other samples in terms of both hydrogen yield and reduction in activation time. The higher activity could be due to higher surface

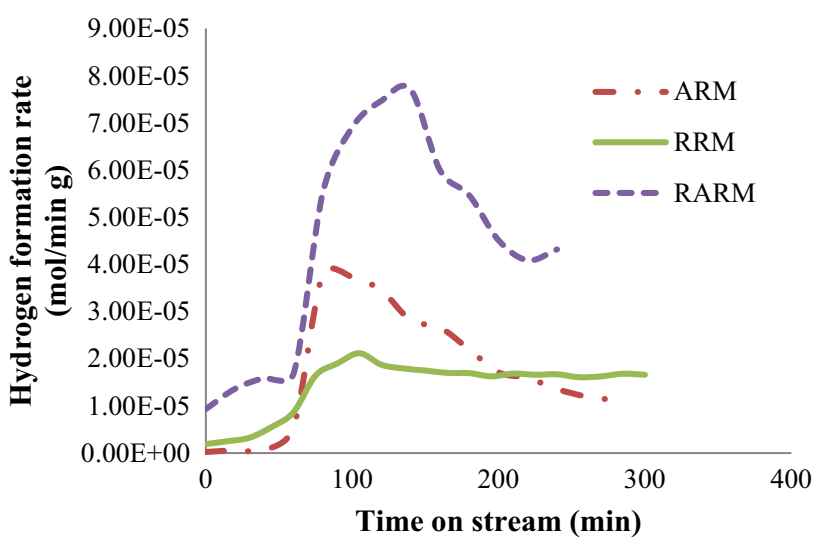

Fig. $6 \mathrm{H}_{2}$ formation rates for cracking of $\mathrm{CH}_{4}(0.2$ slpm $)$ over unmodified and modified red mud at $800{ }^{\circ} \mathrm{C}$ area $\left(72 \mathrm{~m}^{2} / \mathrm{g}\right)$ compared to RRM $\left(24 \mathrm{~m}^{2} / \mathrm{g}\right) ;$ ARM $\left(139 \mathrm{~m}^{2} / \mathrm{g}\right)$ had an even higher surface area but would have needed activation time for reduction of iron oxide to iron and the lower activity could be due to some carbon deposition on the reduced iron. Furthermore, the activation process would have increased the iron content in the red mud and would also be affective in removing sodium and potassium. The hydrogen formation rate increased with increasing temperature. The carbon in the reduced activated red mud sample was a mixture of filaments and spheres and the XRD pattern is indicative of the presence of graphitic carbon (C) and iron (Fe) (Fig. 7). The hydrogen formation rate was also sensitive to flow rate of methane used as shown in Fig. 8 for unmodified red mud. This was similar at other temperatures as well and could due to greater availability of reactant and the kinetics of the reaction.

The performance of the waste from the former nailwork factory was compared in detail with that of unmodified red mud (RM7). Figure 9 shows the hydrogen formation rates for both the waste samples. On increasing the temperature from 600 to $800{ }^{\circ} \mathrm{C}$, it can be seen that the nailwork factory sample showed higher hydrogen formation rate. However, beyond about an hour at $800{ }^{\circ} \mathrm{C}$, the activity of RM7 was superior to that of nailwork factory sample. The difference is due to composition and surface area as explained further below. In addition, a decrease in hydrogen formation rate due to deactivation from carbon deposition was not observed in both samples and activity continued to increase for all samples up to the point at which reaction was stopped. 


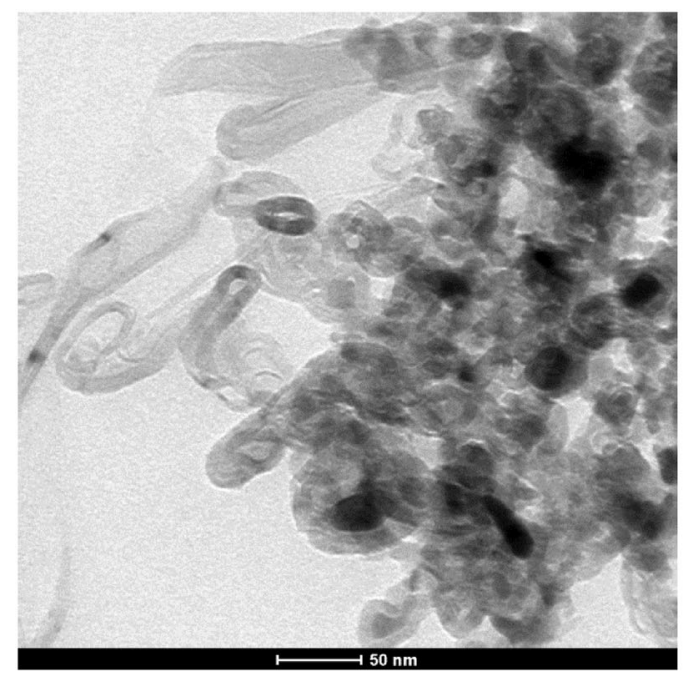

(a)

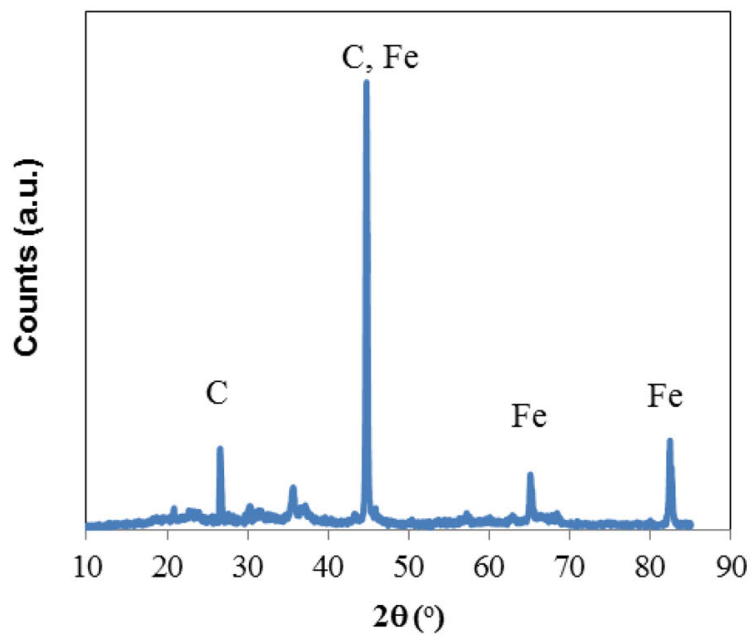

(b)

Fig. 7 a TEM image and b XRD pattern of RARM after methane cracking at $800{ }^{\circ} \mathrm{C}$

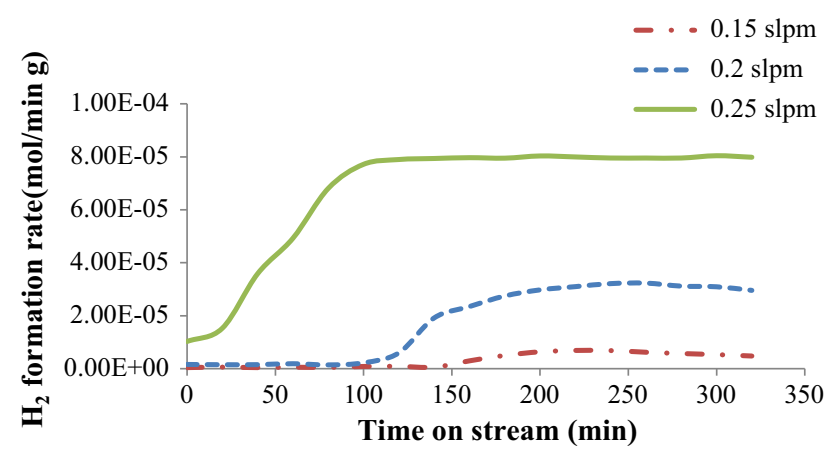

Fig. $8 \mathrm{H}_{2}$ formation rates for cracking of $\mathrm{CH}_{4}$ over unmodified red mud at $800{ }^{\circ} \mathrm{C}$

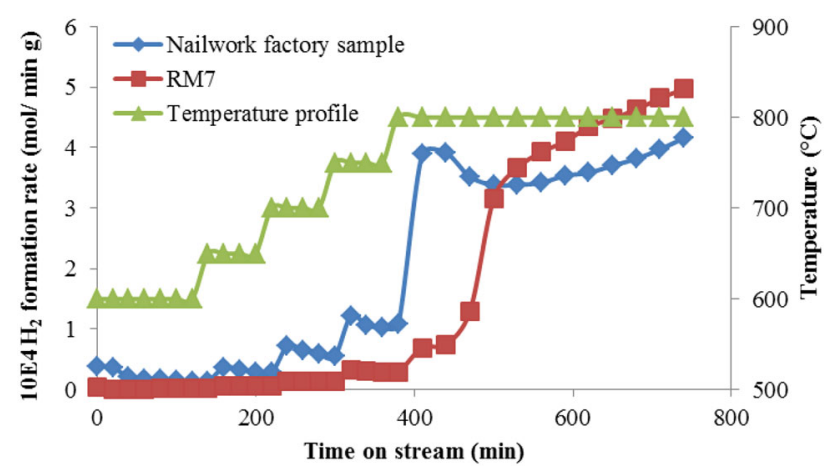

Fig. 9 Hydrogen formation rates as a function of TOS for $\mathrm{CH}_{4}$ decomposition over the nailworks waste and RM7 samples in a temperature-programmed reaction from 600 to $800{ }^{\circ} \mathrm{C}$. The $\mathrm{CH}_{4} / \mathrm{N}_{2}$ flow rate was $12 \mathrm{ml} / \mathrm{min}$ over $0.4 \mathrm{~g}$ sample

The difference in their performance can be attributed to their composition and surface area. As shown in Table 1, the iron content in both the samples is similar. However, the waste from the former nailworks has a higher carbon
Table 1 Composition and surface area of iron-containing waste samples prior to reaction

\begin{tabular}{lll}
\hline & RM7 & Nailwork sample \\
\hline Composition from ICP (wt $\%)$ & \\
$\mathrm{Fe}$ & 25.00 & 22.70 \\
$\mathrm{Al}$ & 10.00 & 3.80 \\
$\mathrm{Si}$ & 9.50 & 24.00 \\
$\mathrm{Ca}$ & 1.60 & 1.44 \\
$\mathrm{Na}$ & 6.10 & 4.80 \\
$\mathrm{~K}$ & 0.36 & 1.25 \\
$\mathrm{Composition}$ from CHN $(\mathrm{wt} \%)$ & \\
$\mathrm{C}$ & $1.00 \pm 0.10$ & $10.70 \pm 0.01$ \\
$\mathrm{H}$ & $1.30 \pm 0.01$ & $1.70 \pm 0.05$ \\
$\mathrm{~N}$ & - & - \\
Surface area $\left(\mathrm{m}^{2} / \mathrm{g}\right)$ & 20 & 43 \\
\hline
\end{tabular}

content and surface area. The higher surface area may have led to higher hydrogen formation rate in the initial stages, while the carbon content may have reduced the reactivity. XRD patterns of the post-reaction samples (Figs. 10 and 11) show the formation of $\mathrm{Fe}, \mathrm{Fe}_{3} \mathrm{C}, \mathrm{SiO}_{2}$, and graphite in the case of RM7 and $\mathrm{FeO}, \mathrm{Fe}_{3} \mathrm{C}, \mathrm{FeFe}_{4}\left(\mathrm{PO}_{4}\right)_{4}(\mathrm{OH})_{2} \cdot 2 \mathrm{H}_{2} \mathrm{O}$, $\mathrm{SiO}_{2}$, and graphite for the nailworks waste. The lower reactivity of the nailwork factory waste sample is also suggested by the fact that the iron may not fully reduced to $\mathrm{Fe}$ and $\mathrm{FeO}$ could be present in the post-reaction sample. As expected, the carbon content in the post-reaction RM7 $(48.40 \pm 0.10 \mathrm{wt} \%)$ was higher than that in the nailwork waste sample $(41.60 \pm 0.20 \mathrm{wt} \%)$. The TGA analysis of post-reaction samples (Fig. 12) shows an initial weight increase between 350 and $500{ }^{\circ} \mathrm{C}$, possibly from the 


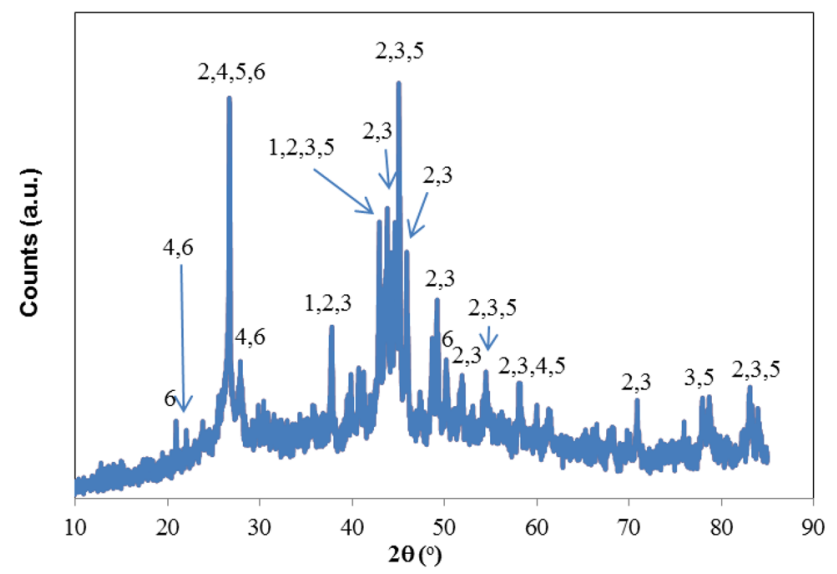

Fig. $10 \mathrm{X}$-ray pattern for the post-reaction nailworks factory sample. 1: iron oxide $(\mathrm{FeO}), 2$ : iron carbide $\left(\mathrm{Fe}_{3} \mathrm{C}\right)$, 3: cohenite $\left(\mathrm{Fe}_{3} \mathrm{C}\right), 4$ : giniite $\left(\mathrm{FeFe}_{4}\left(\mathrm{PO}_{4}\right)_{4}(\mathrm{OH})_{2} \cdot 2 \mathrm{H}_{2} \mathrm{O}\right)$, 5: graphite $(\mathrm{C})$, and 6: quartz $\left(\mathrm{SiO}_{2}\right)$

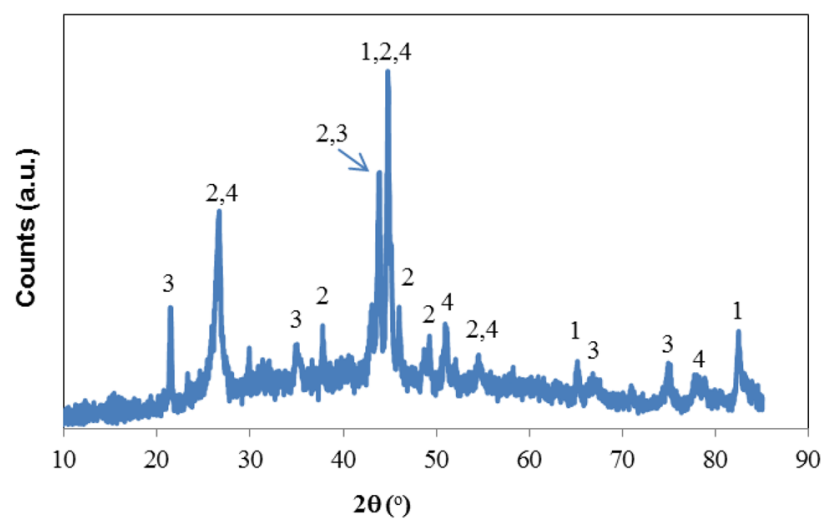

Fig. $11 \mathrm{X}$-ray diffraction pattern for post-reaction RM7 sample. 1: iron $(\mathrm{Fe}), 2$ : iron carbide $\left(\mathrm{Fe}_{3} \mathrm{C}\right), 3$ : quartz $\left(\mathrm{SiO}_{2}\right)$, and 4: graphite $(\mathrm{C})$ oxidation of reduced iron compounds followed by a decrease of up to $700{ }^{\circ} \mathrm{C}$ from carbon oxidation. Post-reaction RM7 with higher carbon content shows a larger weight loss. The first derivative weight change profiles show two mass loss peaks in the nailworks waste at around 480 and $600{ }^{\circ} \mathrm{C}$, which indicate the presence of two different forms of carbon. In the case of the RM7 sample, there is only one broad peak, at approximately $600{ }^{\circ} \mathrm{C}$, which could be attributed to a wide distribution in the nature of the carbonaceous species. Given that the carbon deposits obtained are mostly a mixture of graphite, iron, and iron carbide, they could have further application where magnetic properties are also of relevance such as a separable adsorbent. Similar magnetic material has been made using red mud and ethanol as the carbon source and used for dye removal. Modification by $\mathrm{CO}_{2}$ activation increased the surface area which made it suitable as a support for $\mathrm{Pd}$ catalyst [11]. Other studies have also reported magnetic carbon nanotubes for removal of dyes [12] and chromium [13]. Nitrogen-doped carbon nanotubes have been used for fuel cell applications [14] and have been prepared using iron catalysts [15].

\section{Conclusions}

Red mud and other iron-containing waste samples show potential for use in hydrocarbon cracking leading to the formation of carbon-containing magnetic material in addition to hydrogen generation. Such magnetic composites may find use as easily separable adsorbents. Although such an approach is not likely to address the large amount of red mud being generated, it is an attractive option with

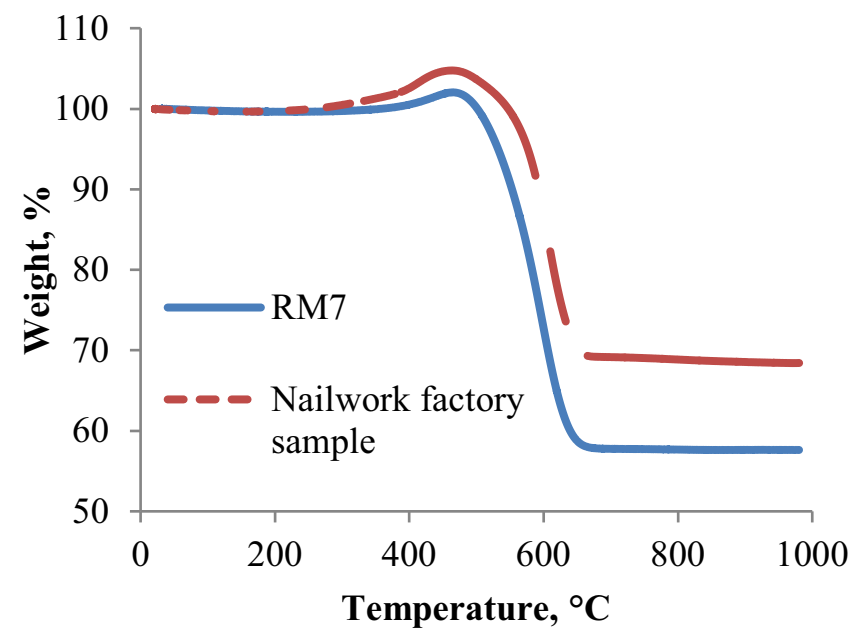

(a)

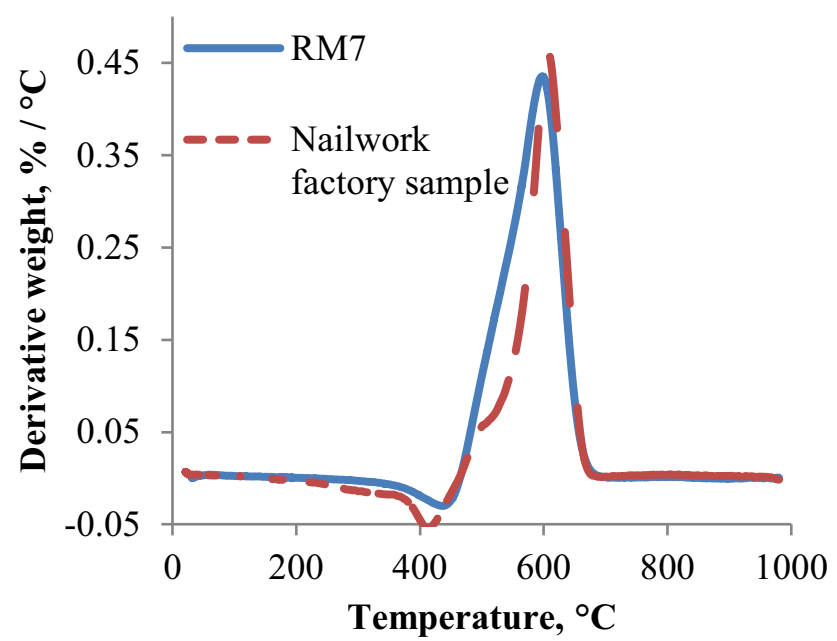

(b)

Fig. 12 TGA a weight loss and b first derivative weight change profiles for the post-reaction nailworks and RM7 samples 
potential for further modification of the carbon deposits for other catalytic and electrochemical applications. In terms of the latter aspect, it is of interest to note that nitrogen functionality can be introduced into the carbon-containing products through the use of acetonitrile as a reagent. Comparative studies have demonstrated a marked influence of the pretreatment of the red mud upon its activity for methane cracking with reduced activated red mud being significantly more active than its activated red mud parent and the red mud sample itself.

Acknowledgments MB, VSB, JSJH, and IDP gratefully acknowledge the British Council for the generous provision of funding through the UKIERI Scheme (Project SA07-19.) AIA and JSJH are very grateful to the Saudi Cultural Bureau for the provision of a Ph.D. studentship to AIA. Mrs Kim Wilson, University of Glasgow, is gratefully acknowledged for her very kind assistance with CHN analysis. Access to the EPSRC XPS service at Cardiff University and the very kind assistance of Dr David Morgan are also gratefully acknowledged. The authors wish to express their appreciation to $\mathrm{Mr}$ Matar Alshalwi of King Saud University for very kindly conducting the ICP analyses.

\section{References}

1. Wang S, Ang HM, Tadé MO (2008) Novel applications of red mud as coagulant, adsorbent and catalyst for environmentally benign processes. Chemosphere 72(11):1621-1635

2. Sushil S, Batra VS (2008) Catalytic applications of red mud, an aluminium industry waste: a review. Appl Catal B 81(1):64-77

3. Balakrishnan M, Batra VS, Hargreaves JSJ, Pulford ID (2011) Waste materials-catalytic opportunities: an overview of the application of large scale waste materials as resources for catalytic applications. Green Chem 13(1):16-24

4. Balakrishnan M, Batra VS, Hargreaves JSJ, Monaghan A, Pulford ID, Rico JL, Sushil S (2009) Hydrogen production from methane in the presence of red mud-making mud magnetic. Green Chem 11(1):42-47

5. Sushil S, Alabdulrahman AM, Balakrishnan M, Batra VS, Blackley RA, Clapp J, Hargreaves JSJ, Monaghan A, Pulford ID, Rico JL, Zhou W (2010) Carbon deposition and phase transformations in red mud on exposure to methane. J Hazard Mater 180(1):409-418

6. Pulford ID, Hargreaves JSJ, Ďurišová J, Kramulova B, Girard C, Balakrishnan M, Batra VS, Rico JL (2012) Carbonised red mud-a new water treatment product made from a waste material. J Environ Manage 100:59-64

7. Gaudino S, Galas C, Belli M, Barbizzi S, Zorzi P, Jaćimović R, Jeran Z, Pati A, Sansone U (2007) The role of different soil sample digestion methods on trace elements analysis: a comparison of ICP-MS and INAA measurement results. Accredit Qual Assur 12:84-93

8. Balakrishnan M, Batra VS, Durisova J, Gupta N, Hargreaves JSJ, Pulford ID, Rico JL, Singh RK (2010) Transformations in red mud on hydrocarbon exposure and subsequent application for water remediation. In: Second international symposium on green chemistry for environment and health 27-29 September 2010 Mykonos Greece

9. Hachimi A, Merzougui B, Hakeem A, Laoui T, Swain GM, Chang Q, Shao M, Atieh MA (2015) Synthesis of nitrogen-doped carbon nanotubes using injection-vertical chemical vapor deposition: effects of synthesis parameters on the nitrogen content. J Nanomater. doi:10.1155/2015/453725

10. Hao Y, Qingwen L, Jin Z, Zhongfan L (2003) The effect of hydrogen on the formation of nitrogen-doped carbon nanotubes via catalytic pyrolysis of acetonitrile. Chem Phys Lett 380(3):347-351

11. Oliveira AA, Tristão JC, Ardisson JD, Dias A, Lago RM (2011) Production of nanostructured magnetic composites based on $\mathrm{Fe}^{0}$ nuclei coated with carbon nanofibers and nanotubes from red mud waste and ethanol. Appl Catal B 105(1):163-170

12. Gong JL, Wang B, Zeng GM, Yang CP, Niu CG, Niu QY, Zhou WJ, Liang Y (2009) Removal of cationic dyes from aqueous solution using magnetic multi-wall carbon nanotube nanocomposite as adsorbent. J Hazard Mater 164(2):1517-1522

13. Gupta VK, Agarwal S, Saleh TA (2011) Chromium removal by combining the magnetic properties of iron oxide with adsorption properties of carbon nanotubes. Water Res 45(6):2207-2212

14. Shao Y, Sui J, Yin G, Gao Y (2008) Nitrogen-doped carbon nanostructures and their composites as catalytic materials for proton exchange membrane fuel cell. Appl Catal B 79(1):89-99

15. Nath M, Satishkumar BC, Govindaraj A, Vinod CP, Rao CNR (2000) Production of bundles of aligned carbon and carbon-nitrogen nanotubes by the pyrolysis of precursors on silica-supported iron and cobalt catalysts. Chem Phys Lett 322(5):333-340 